\title{
A new baenid turtle from the early Paleocene (Torrejonian) of New Mexico and a species-level phylogenetic analysis of Baenidae
}

\author{
Tyler R. Lyson, ${ }^{1}$ Walter G. Joyce, ${ }^{2}$ Spencer G. Lucas, ${ }^{3}$ and Robert M. Sullivan ${ }^{3}$ \\ ${ }^{1}$ Department of Earth Sciences, Denver Museum of Nature and Science, 2001 Colorado Boulevard, Denver, Colorado 80205, USA \\ 〈tyler.lyson@dmns.org \\ ${ }^{2}$ Department of Geosciences, University of Fribourg, Chemin du Musée 6, 1700 Fribourg, Switzerland 〈walter.g.joyce@ gmail.com〉 \\ ${ }^{3}$ New Mexico Museum of Natural History and Science, 1801 Mountain Road NW, Albuquerque, New Mexico 87104, USA 〈spencer.lucas@state.nm.us〉, \\ 〈r.sullivan45@comcast.net〉
}

\begin{abstract}
New cranial and postcranial material of the baenid turtle Neurankylus from the Paleocene Nacimiento Formation (Torrejonian NALMA) of northwestern New Mexico represents a new species, Neurankylus torrejonensis. The material consists of a fragmented but mostly complete skull, a partial carapace and plastron, portions of both humeri, a partial pelvis, a complete right femur, and a distal phalanx. The small, undivided cervical scale, wide vertebrals, complete ring of marginals, and large size (carapace length $520 \mathrm{~mm}$ ) diagnose the new taxon as belonging to Neurankylus. The narrow fifth vertebral scale and scalloped posterior shell margin reveal affinities with Neurankylus baueri Gilmore, 1916, which is known from Campanian sediments in New Mexico and Utah. The holotype of Neurankylus torrejonensis is the youngest known specimen of the Neurankylus lineage, which is known to reach at least back to the Late Cretaceous (Santonian). A nearly complete species-level analysis of baenids confirms the basal placement of Neurankylus outside of Baenodda and the split of Baenodda into two primary subclades, herein named Palatobaeninae and Eubaeninae.
\end{abstract}

\section{Introduction}

Baenid turtles are the most common and speciose group of turtles in North American Upper Cretaceous to Paleogene sedimentary rocks (Hay, 1908; Gaffney, 1972; Archibald, 1977; Holroyd and Hutchison, 2002; Joyce and Lyson, 2015). Baenids are endemic to North America and appear to have occupied a number of ecological niches. These medium to large freshwater turtles have a wide array of both skull shapes, from elongate to triangular to round, and triturating surfaces, from narrow to greatly expanded, which indicate a diversity of dietary niches (Archibald and Hutchison, 1979; Holroyd and Hutchison, 2002; Lyson and Joyce, 2009a, b). While most representatives of the group are found in sandstone, interpreted as riverine deposits, some members are more commonly found in fine-grained overbank deposits (e.g., Boremys spp. [Lyson et al., 2011]).

The excellent fossil record of baenids is largely because (1) most representatives of this clade were riverine and therefore have a high preservation potential (Russell, 1934; Lyson and Joyce, 2009a) and (2) many baenid taxa fused their shell as adults, so complete shells are common (Hutchison, 1984). Pieces of baenid shell are one of the most common fossils found in latest Cretaceous and Paleogene rocks (Hutchison and Archibald, 1986; Holroyd and Hutchison, 2002; Hutchison and Holroyd, 2003; Hutchison et al., 2013). However, while baenid shells are common, skulls and skull-shell associations are not. Of the 29 previously recognized baenid taxa (Joyce and Lyson, 2015), only eleven taxa are known from both skulls and shells.
Among basal baenids, skull-shell associations only exist for Trinitichelys hiatti (Gaffney, 1972). Isolated skulls from the basal baenid Neurankylus spp. have been reported from the Dinosaur Park (Campanian) and Milk River (Santonian) formations, which have been referred to Neurankylus eximius (Brinkman and Nicholls, 1993) and Neurankylus lithographicus (Larson et al., 2013), respectively. However, both known skulls of Neurankylus spp. are fragmentary, only consisting of a partial skull roof and basicranium. Here we describe moderately complete skull, shell, and postcranial elements from a new species of Neurankylus from the Torrejonian (Paleocene) of New Mexico. We also conduct the first species-level analysis of all 30 currently recognized species of baenids (Joyce and Lyson, 2015) and discuss the paleobiology of this large baenid turtle.

\section{Systematic paleontology}

Testudinata Klein, 1760

Paracryptodira Gaffney, 1975

Baenidae Cope, 1873

Neurankylus Lambe, 1902

Type species.—Neurankylus eximius Lambe, 1902.

Other species.-Neurankylus eximius; Neurankylus baueri Gilmore, 1916; Neurankylus lithographicus Larson et al., 2013; Neurankylus torrejonensis $\mathrm{n}$. sp. 
Remarks.-For a recent review of taxa classified within Neurankylus, please refer to Larson et al. (2013) and Joyce and Lyson (2015).

\section{Neurankylus torrejonensis new species} Figures 2-5

Holotype.-New Mexico Museum of Natural History and Science (NMMNH) P-9049, a fragmentary skeleton, including skull, lower jaws, shell, and associated postcranial elements (Figs. 2-5). The holotype was found in section 32, T21N, R4W, (Ojo Encino Mesa, N.M. 71/2 minute USGS topographic map) along the east flank of Torreon (a.k.a. Torrejon) Wash, Sandoval County, New Mexico. The locality is situated in the Nacimiento Formation within the 'Upper Fossil Level, Torrejon' of Sinclair and Granger's (1914) locality number eleven. The turtle was found in red clay shale about 25 meters below the unconformable contact of the overlying San Jose Formation with the Nacimiento Formation (Fig. 1).

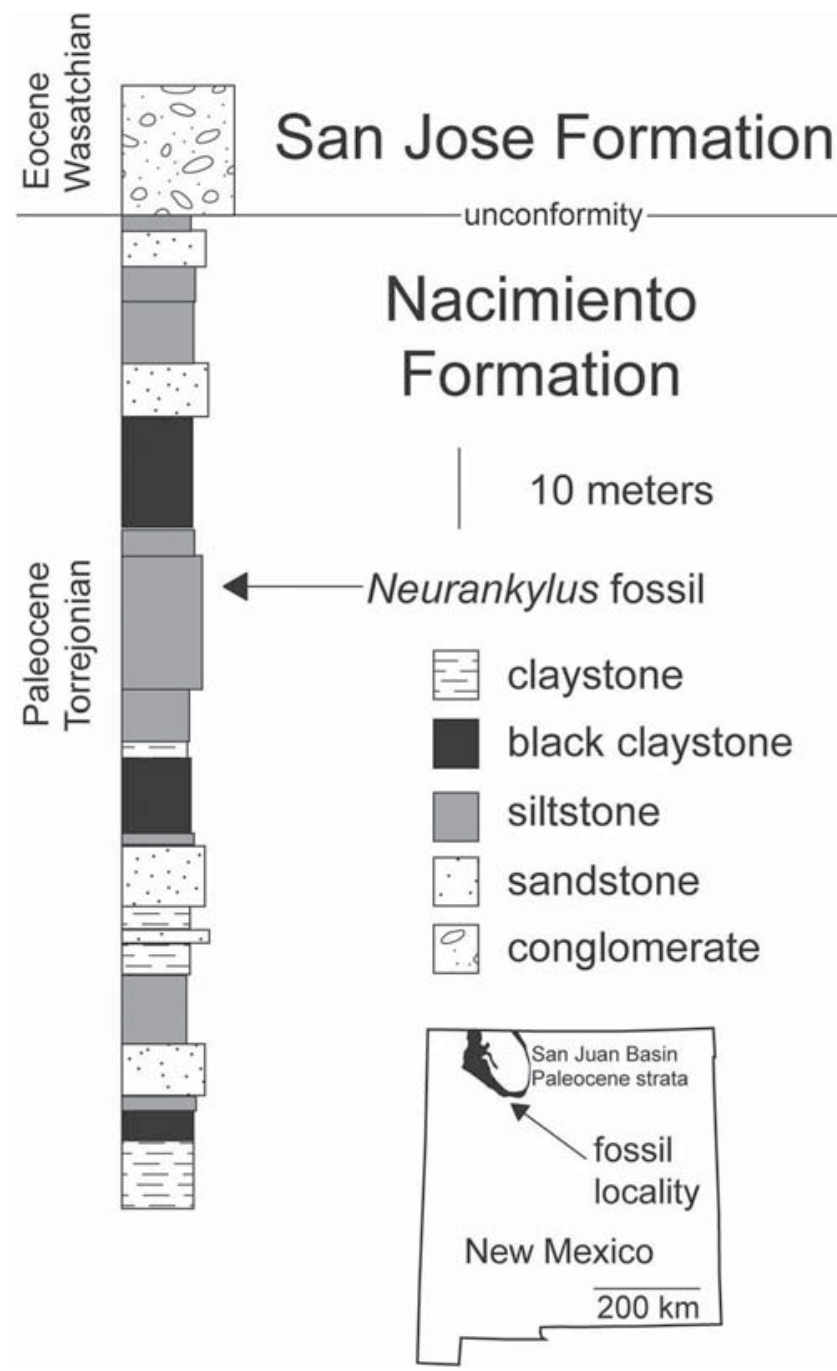

Figure 1. Map of New Mexico and stratigraphic column showing the geographic (San Juan Basin) and stratigraphic (Paleocene Torrejonian North American Land Mammal 'Age') location of where the holotype of Neurankylus torrejonensis (NMMNH P-9049) was found.
The locality at which the specimen was collected, as well as stratigraphically equivalent localities within one-half kilometer, produced a typical assemblage of early Paleocene mammals. Indeed, these strata are part of the 'type area' for the early Paleocene Torrejonian North American Land Mammal 'Age' (NALMA; Wood et al., 1941). Thus, the early Paleocene age of the specimen seems certain.

Diagnosis.- The new taxon can be diagnosed as a member of Paracryptodira because of the location of the foramen posterius canalis carotici interni halfway along the pterygoid and basisphenoid suture, a member of Baenidae because of the presence of a wedge-shaped skull, a well-developed pterygoid and basioccipital contact, and strong axillary and inguinal buttresses that contact the costals dorsally, and a member of Neurankylus because of its large size (carapacial length $>500 \mathrm{~mm}$ ), smooth rounded shell that lacks both anterior and posterior notches, complete ring of marginal scales, wide vertebral scales, lack of contact between the gular scales, broad exposure of the prefrontals on the dorsal skull roof, large nasals, no upper temporal emargination, small and triangular basisphenoid, complete lingual and labial ridges on the lower jaw, and a deep and distinctly hooked dentary. Neurankylus torrejonensis is currently differentiated from all Neurankylus by a narrow fifth vertebral scale, a scalloped posterior edge of the shell, no upper temporal emargination in the skull, broad exposure of the parietals overtop the supraoccipital, and a large prefrontal exposure on the dorsal skull roof. Neurankylus torrejonensis is also the only species of Neurankylus that completely fuses up its shell as an adult.

Description.-The specimen was found disarticulated and broken into several pieces exposed on the western slope of a north-south running gully. The carapace was shattered with only few pieces larger than a few square centimeters still intact. Most of the breaks are fairly 'fresh' (i.e., recent in occurrence, edges sharp with bone along the fracture face very dark), indicating mechanical breakup at the surface. There are, nevertheless, some distortions as well as weathered fractures in some parts of the shell and particularly in the more delicate skull. Most of this damage therefore probably occurred prior to fossilization.

Although the specimen is not articulated, we are confident that the remains are from a single animal. The skull and cervical vertebrae were found adjacent to one another within 25 centimeters of the carapace. The appendicular skeleton and caudal vertebrae were found intermingled with the shell fragments. In addition to the close proximity of the chelonian remains, the similarities in preservation of the skull and shell also tend to support their derivation from a single individual. Although the vertebral centrum of a crocodile, a coprolite, and the molar teeth of several genera of mammals were found near the specimen, no other turtle remains were found on the slope. Combined, these data indicate the skull and carapace belonged to one individual.

Skull.- The skull is heavily fragmented and could be reassembled into three large fragments that consist of most of the dorsal skull roof, the basicranium, and the quadrates and dorsal ear region, but only the dorsal skull roof shows substantial amounts of morphology and is figured here (Fig. 2). Little information from the palate is available as this region is either missing or 


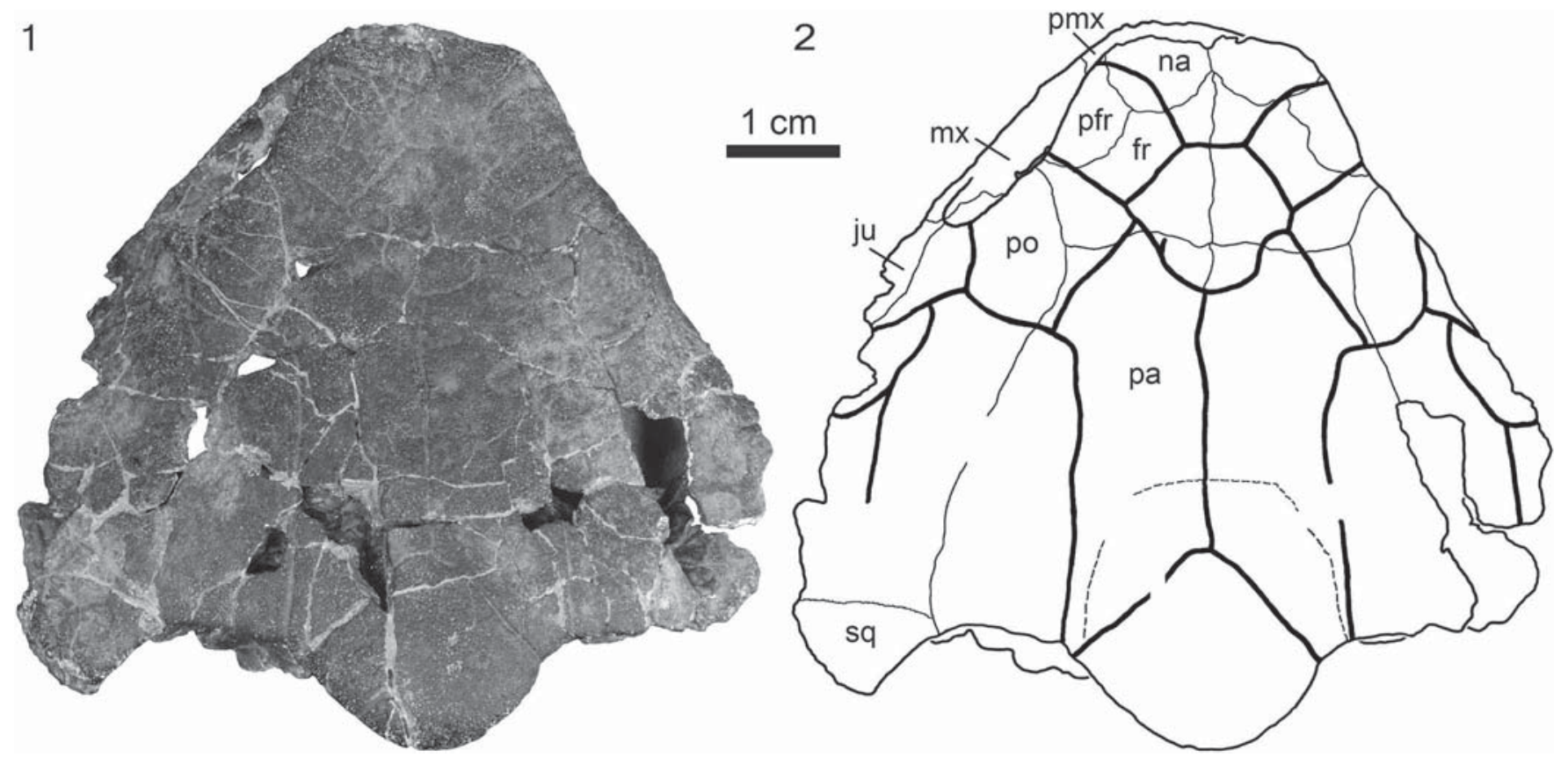

Figure 2. The dorsal skull roof of the holotype of Neurankylus torrejonensis (NMMNH P-9049), Paleocene (Torrejonian) of New Mexico. (1) Photograph of the specimen; (2) line drawing of the specimen with sutures (thinner lines) and scale pattern (thicker lines). $\mathrm{fr}=\mathrm{frontal}$; ju $=\mathrm{jugal}$; $\mathrm{mx}=\mathrm{maxilla}$; na $=\mathrm{nasal}$; $\mathrm{pa}=$ parietal; $\mathrm{pfr}=$ prefrontal; $\mathrm{pmx}=$ premaxilla; $\mathrm{po}=$ postorbital; $\mathrm{sq}=$ squamosal.

highly fragmented and sutures could not be discerned. The skull is large with a length of $97 \mathrm{~mm}$ and a width of $97.5 \mathrm{~mm}$, larger than any other baenid. The skull is wedge shaped, as in other baenids, but the anterior margin of the skull is flattened, and the nares are oriented toward the anterior. The posterior margin of the skull is characterized by a sinusoidal outline created by rounded squamosal horns, shallow upper temporal emarginations that fully cover the otic chamber in dorsal view, and a broad and rounded roofing of the crista supraoccipitalis by either the supraoccipital or parietals (see the following). Only the anterior portion of the lower temporal margin is preserved on the left side, revealing that this emargination was present but shallow. The distance between the orbits is wide, and the orbits are oriented laterally. A distinct sulcus pattern is visible on the dorsal skull roof (Fig. 2).

Nasals.-The nasals are large, rectangular elements that extend anteriorly as far as the underlying premaxillae. The nasals contact the maxillae laterally, the prefrontals and frontals posteriorly, and one another medially. Unlike other baenids, a large nasal and prefrontal contact is present that prevents the frontals from contacting the maxillae. Like the basal baenids Hayemys latifrons Gaffney, 1972 and Trinitichelys hiatti Gaffney, 1972, the nasals are large, but the nasals do not extend as far posteriorly as they do in T. hiatti.

Prefrontals.-Unlike all baenids except $H$. latifrons, the dorsal plate of the prefrontal is large, but not large enough to contact one another along the midline. The large dorsal exposure of the prefrontal, nevertheless, almost hinders the frontals from entering the orbital margin. Unlike $H$. latifrons, but similar to other baenids and paracryptodires that have a dorsal prefrontal exposure, the prefrontal does not contact the postorbital. Instead, it contacts the frontal posteriorly and medially, and the nasal anteriorly. The descending processes of the prefrontals are both broken, but the thickness of the bone at the breaks clearly reveals that the descending processes were well developed.

Frontals.-The frontals are greatly reduced in $N$. torrejonensis relative to $H$. latifrons and $T$. hiatti, where they extend well beyond the posterior rim of the orbit. The maximum combined width of the frontals is significantly larger than their length. Posteriorly, the frontals form a slightly sinuous contact with the parietals. A small portion of both frontals enters the orbital margins between the greatly expanded prefrontals and the postorbitals. Unlike other baenids, the frontal does not form an anterolateral contact with the maxilla. The ventrally developed sulcus olfactorius is rather broad, about one-third of the interorbital width.

Parietals.-Similar to other baenids, except $H$. latifrons, Baena arenosa Leidy, 1870 (sensu Joyce and Lyson, 2015), and Chisternon undatum Leidy, 1871b, the parietals are longer than their maximum combined width and thereby form the majority of the skull roof. The posterior margin of the skull roof is only slightly emarginated. No portion of the underlying otic capsule is exposed in dorsal view. The parietals form a long contact with the postorbital laterally and a small contact with the squamosal posterolaterally. It is unclear to us whether the supraoccipital broadly contributes to the dorsal skull roof (see 'Supraoccipital' in the following). The parietals therefore either have a broad posteromedial contact with the supraoccipital or fully cover the supraoccipital crest.

Jugal.- The lateral portion of the skull is crushed, greatly obscuring the left jugal. The right jugal is missing completely. It is nevertheless apparent that the jugal narrowly enters the orbital margin anteriorly and contacts the maxilla anteroventrally and the postorbital medially.

Quadratojugal._-The quadratojugals are missing completely. 
Squamosal.-Most of the squamosals are missing, with the exception of the posterior contribution of the left squamosal to the skull roof. As in other turtles, it is situated on the posterolateral portion of the skull. The squamosal contacts the parietal along a short suture medially, therefore hindering the postorbital from entering the upper temporal emargination, broadly contacts the postorbital anteriorly, and forms the lateral portion of the upper temporal emargination.

Postorbital.-As in other baenids, the postorbital forms a broad bar on the dorsolateral portion of the skull and forms the majority of the posterodorsal portion of the orbital margin. A small process of the postorbital extends dorsally over the orbit, which, together with the large prefrontal, greatly constricts the frontal contribution to the orbital margin. Unlike other baenids, with the exception of B. arenosa (sensu Joyce and Lyson, 2015) and $C$. undatum, the postorbital does not form any portion of the temporal emargination, being restricted by a squamosal and parietal contact. The postorbital does not contact the maxilla, as in some baenodds. The postorbital contacts the jugal anteroventrally, the quadratojugal likely posteroventrally, and the squamosal posteriorly.

Premaxilla.-The labial ridge is the only portion of the premaxillae that is preserved. In anterior view, the premaxillae slope upward toward their medial midline contact and create an angle of approximately $90^{\circ}$. This accommodates the symphyseal hook (see the following) of the lower jaw, allowing for full closure of the jaws. The only other apparent contact is the posterolateral contact of the premaxillae with the maxillae.

Maxilla.- The preserved portion of the maxilla is a bar in the floor of the orbit. The orbit is situated vertically above the maxilla and is not inset relative to the maxilla as in Cedrobaena putorius (Gaffney, 1972), Gamerabaena sonsalla Lyson and Joyce, 2010, and Palatobaena spp. The ascending process of the maxilla contacts the nasal and prefrontal dorsally and forms the lateral portion of the apertura narium externa. A contact is absent between the maxilla and frontal, unlike all other known baenids. Posteriorly, the maxilla contacts the jugal. A small portion of the maxillary contribution to the palate is preserved attached to the braincase. This fragment confirms the posteromedial contact of the maxilla with the palatine and pterygoid, reveals that the maxilla contributed to the anterolateral rim of the foramen palatinum posterius, and reveals the presence of a low lingual ridge. However, it is not possible to assess the extent of the lingual ridge.

Vomer.-The vomer is not preserved.

Palatine.-Only the posterior portions of the palatines are preserved attached to the braincase. The palatines are plate-like structures that roof the internal choanae, as in other baenids, and contact the maxilla anterolaterally and the pterygoid posteriorly. The left foramen palatinum posterior is well preserved, and it is apparent that the palatine only forms the posteromedial aspect of this foramen.

Quadrate.-The quadrates are partially preserved, including both articular rami and portions of the otic roofing and cavum tympani. As in other baenids, the quadrate is a stout, $\mathrm{C}$-shaped bone. Within the temporal cavity, what is preserved of the quadrates forms a broad anterolateral contact with the prootic. Unlike Palatobaena spp. and Ce. putorius, but similar to other baenids, the condylus mandibularis is relatively small.
Pterygoid.-The pterygoids are too badly damaged to determine any of their sutural contacts.

Supraoccipital.- It is unclear to us whether the supraoccipital is fully covered by the parietals, as in $N$. eximius (Brinkman and Nicholls, 1993; Larson et al., 2013), or contributes broadly to the posterior skull roof. The presence of a large supraoccipital is favored by the lack of an apparent midline suture of the parietals in the posterior region of the skull and by breaks that outline an area similar to other turtles with a large dorsal exposure of the supraoccipital, such as Meiolania platyceps (Gaffney, 1983). The lack of a dorsal supraoccipital contribution is supported by a suture-like break between the skull roof and the crista occipitalis and by the asymmetric placement of the supposed supraoccipital to the right of the midline. The supraoccipital unambiguously roofs the foramen magnum and the brain cavity and, as in all turtles, laterally contacts the prootic and opisthotic within the upper temporal fossa.

Exoccipital.-Only those portions of the exoccipital that contribute to the occipital condyle are preserved in the specimen.

Basioccipital.-The basioccipital is present but poorly preserved. It contacts the basisphenoid anteriorly, the pterygoids anterolaterally, and the exoccipitals posterolaterally. One pair of prominent, posteriorly oriented tubercula basioccipitale is formed solely by the basioccipital. A semicircular depression is apparent between the tubercula that is formed solely by the basioccipital as well. A pair of foramina is positioned at the center of this depression just anterior to the shaft of the occipital condyle. Our observations of skull material indicate that these foramina are widely distributed among baenids, but we are uncertain as to their homology.

Prootic/opisthotic.- The prootic and opisthotic region is badly damaged, and we are therefore not able to discern any relevant anatomical details.

Basisphenoid.- The basisphenoid is complete but poorly preserved. It contacts the pterygoids anterolaterally and the basioccipital posteriorly.

Lower jaw.- The lower jaw is beautifully preserved with little distortion. However, all sutures are completely closed, so we only discuss the shape of the jaw. The mandible is very distinct from those of all other baenids. The lower jaw is very deep but has notably narrow triturating surfaces. A distinct midline projection of the labial ridge forming a symphyseal 'hook' is present, similar to that found in Glyptops plicatulus Cope, 1877 . The angle between the rami is broad, roughly $90^{\circ}$, and therefore broader than that found in all baenodds except Palatobaena spp. Unlike other baenids, a distinct lingual ridge is present and runs along the entire length of the dentary. The lingual ridge is nearly as high as the labial ridge, a character that is not found on any other baenid. As in G. plicatulus, the lingual and labial ridges are roughly parallel to one another. The posterior portion of the labial ridge is weakly serrated. The coronoid process is well developed. The splenial bone appears to be absent (Fig. 3).

Shell.-The shell is highly fragmented due to mechanical erosion. Portions of both the carapace and plastron were pieced together, but significant portions are missing (Fig. 4). The plastron is estimated to be $420 \mathrm{~mm}$ long. The carapace is oblong in shape with parallel sides and has an estimated length 

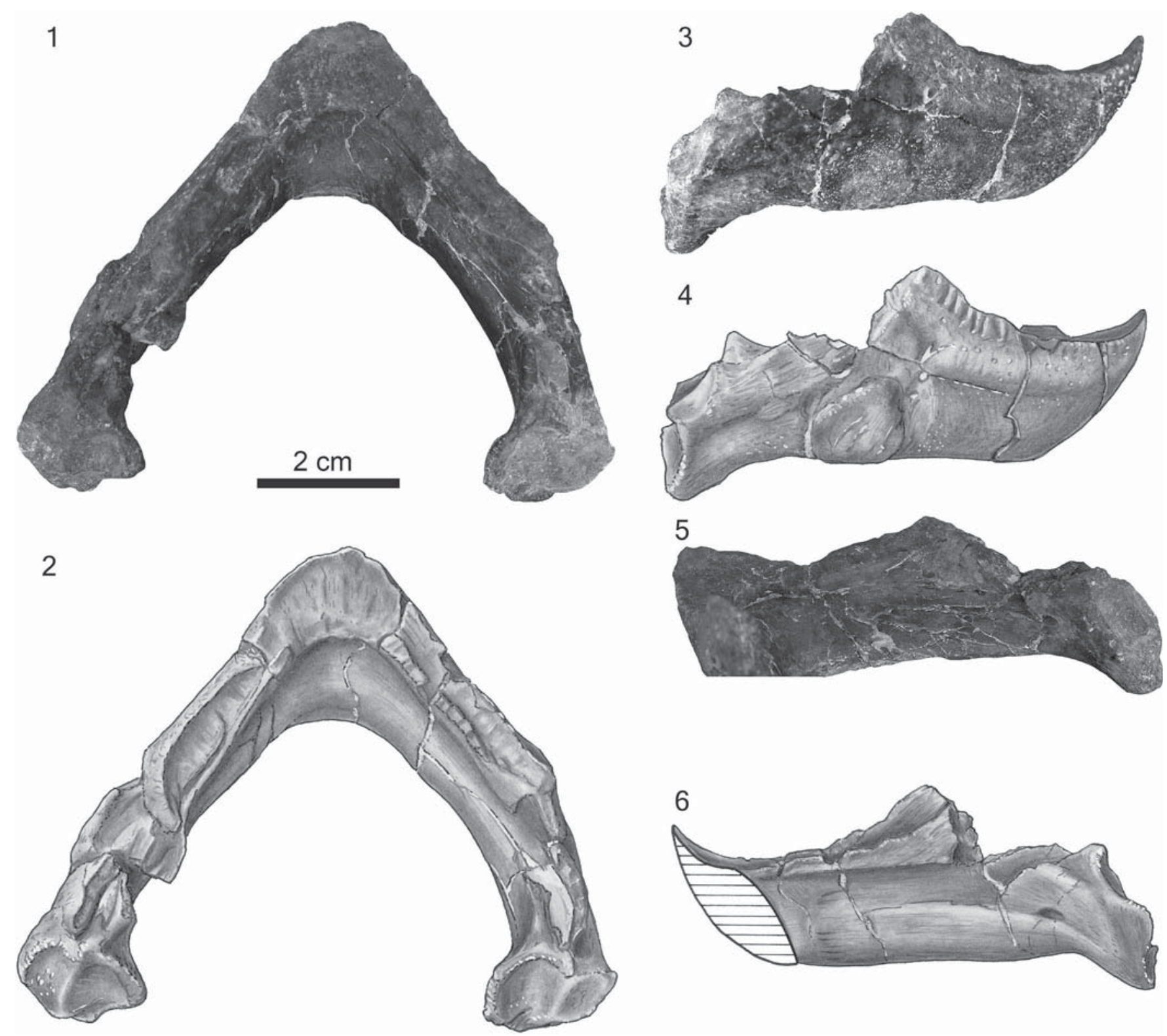

Figure 3. The lower jaw of the holotype of Neurankylus torrejonensis (New Mexico Museum of Natural History and Science P-9049), Paleocene (Torrejonian) of New Mexico. (1) Photograph and (2) illustration in dorsal view; (3) photograph and (4) illustration in lateral view; (5) photograph and (6) illustration in medial view.

of $520 \mathrm{~mm}$. Shell ornamentation is absent. Only a small portion of the posterior margin of the shell is preserved, which indicates it was likely weakly scalloped. The shell is completely fused, so we only describe the scale morphology.

Five vertebral scales are present. These scales are slightly wider than they are long. The first, fourth, and fifth vertebrals are hexagonal, while the second and third vertebrals are rectangular in shape. Like $N$. baueri, the fifth vertebral is not as wide as vertebrals 1-4. As in other Neurankylus spp., the fifth vertebral does not contribute to the posterior margin of the shell.

A small rectangular cervical scale bordered laterally by the first marginals is present. Four pleural scales are present, and all types of supernumerary scales found in other baenids are missing. The first three marginal scales on both sides of the shell and last six marginal scales on the right side of the shell are preserved. The first vertebral scale contacts marginal scales 1 and 2 . The fifth vertebral scale contacts marginal scales 11 and 12 .

A pair of gular and extragular scutes are present. As in $N$. baueri (Sullivan et al., 2013), the gular scutes are large and prevent the smaller extragular scutes from meeting one another along the midline. Both the gular and extragulars are rectangular in shape. The humerals broadly cover the posterior portion of the rectangular anterior plastral lobe. The pectorals are large, rectangular elements that contact three inframarginals laterally. The abdominals are slightly smaller than the pectorals and contact two inframarginals laterally. Most of the posterior plastral lobe is missing, and little can therefore be said about the femoral and anal scales. However, it appears that the anal scale is small and restricted to the posterior end of the posterior plastral lobe (Fig. 4). 

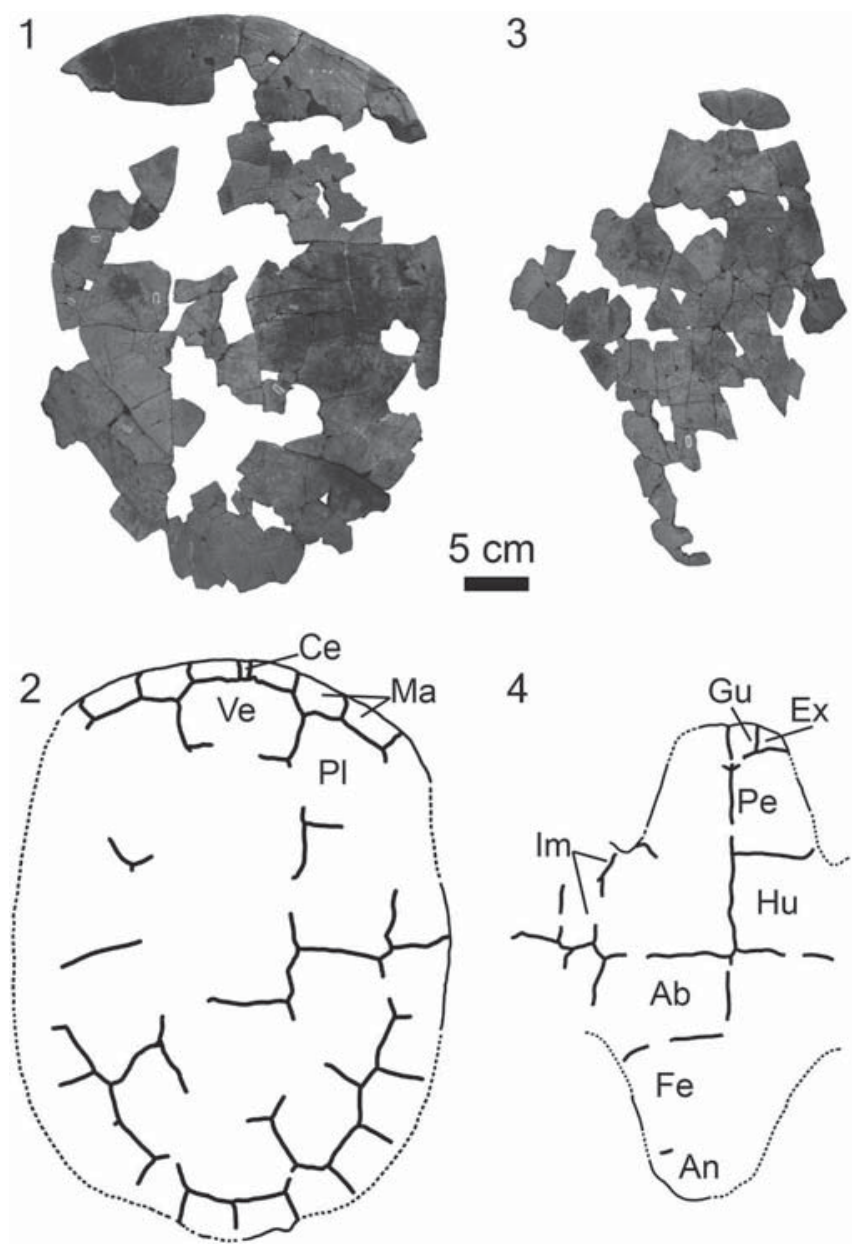

Figure 4. The carapace and plastron of the holotype of Neurankylus torrejonensis (NMMNH P-9049), Paleocene (Torrejonian) of New Mexico. (1) Photograph and (2) line drawing of the carapace; (3) photograph and (4) line drawing of the plastron. $\mathrm{Ab}=$ abdominal scute; $\mathrm{An}=$ anal scute; $\mathrm{Ce}=$ cervical scute; $\mathrm{Ex}=$ extragular scute; $\mathrm{Fe}=$ femoral scute $\mathrm{Gu}=$ gular scute; $\mathrm{Hu}=$ humeral scute; $\mathrm{Im}=$ inframarginal scute; $\mathrm{Ma}=$ marginal scute; $\mathrm{Pe}=$ pectoral scute; $\mathrm{Pl}=$ pleural scute; $\mathrm{Ve}=$ vertebrate scute.

Humerus.- Only the ends of both humeri are preserved, and the length of this element is therefore not known (Figs. 5.4-6). The proximal end has a small, circular head with a relatively small lateral process but a large and widely splayed medial process. The shaft of the humerus is cylindrical. The ectepicondyle and entepicondyle are well developed and are distinctly separated from one another, and the ectepicondylar canalis is enclosed.

Pelvis.-The pelvis is preserved in two pieces consisting of the left ilium, acetabulum, and portions of the ischium (Fig. 5.1) and a large piece of the ossified epipubis (Fig. 5.2). The distal fan is significantly broader in all baenodds for which this structure is known (Hay, 1908; Brinkman, 2003; Lyson and Joyce, 2009b). The ilium possesses a well-defined shaft and expands distally into an anteroposteriorly oriented fan. The acetabulum is fused. A fully ossified, long, but incomplete, epipubic process is present.

Femur.-The right femur is well preserved (Fig. 5.3). As in other turtles, the shaft is cylindrical and slightly S-shaped. The femoral head is large and oval shaped. The proximal end of the femur has two well-developed trochanters (major and minor) that are both distinct from the femoral head. The distal end of the femur consists of two condyles that are distinctly separated from one another.

Distal phalanx.-A single distal phalanx is preserved. It is approximately $2 \mathrm{~cm}$ in length. The width approximates the height. A distinct tubercle is present on the ventral surface near the proximal end.

Etymology.-The species epithet is derived in reference to the type locality at Torreon Wash and the Torrejonian NALMA.

Referred specimens.-No specimens are referred. The specific affinities of slightly older (Puercan NALMA) material from nearby localities (e.g., Sullivan et al., 1988) remain uncertain.

\section{Materials and methods}

Phylogenetic analysis.-To illuminate the phylogenetic affinities of Neurankylus torrejonensis, we performed an expanded analysis of baenid relationships by modifying the successive phylogenetic analyses of Lyson and Joyce (2009a, b, 2010, 2011) and Lyson et al. (2011). The alpha taxonomy of our new analysis follows Joyce and Lyson (2015) by recognizing 30 valid baenid taxa, including Neurankylus torrejonensis $\mathrm{n}$. sp. The most notable new insight from the novel taxonomy of Joyce and Lyson (2015) is the recognition of four valid Eocene taxa (i.e., Baena arenosa Leidy, 1870; 'Baena' affinis Leidy, 1871a; Chisternon undatum [Leidy, 1871b]; and Palatobaena gaffneyi Archibald and Hutchison, 1979) and the polyphyletic nature of Baena arenosa sensu Gaffney (1972). Of 30 valid species, three are excluded from the matrix (i.e., Thescelus insiliens Hay, 1908, Thescelus rapiens Hay, 1908, and Protobaena wyomingensis [Gilmore, 1920]) because these taxa need redescription. However, the sample was expanded through the addition of two undescribed taxa, informally referred to as ND1 and ND2, based on extensive material from North Dakota. Given that the ingroup of our analysis is focused on Baenidae, not Paracryptodira, we omitted numerous characters relative to previous analyses because they had been rendered parsimony uninformative for the new sample. The final character/taxon matrix consists of 33 taxa (30 ingroup and 3 outgroup taxa) and 69 characters with 86 derived character states, of which 15 form morphoclines that can be ordered. Our source of morphological information is listed in Appendix 1; the final character list is in Appendix 2; and our character/taxon matrix is in Appendix 3.

\section{Results}

A phylogenetic analysis was performed using TNT (Goloboff et al., 2008) consisting of 1,000 Wagner tree replicates, followed by a TBR cycle. All multistate characters that form morphoclines were ordered. A consensus tree of the 292 obtained most parsimonious trees of 168 steps is provided in Figure 6.

\section{Discussion}

The herein described partial skeleton belonging to Neurankylus torrejonensis $\mathrm{n}$. sp. provides important anatomical details for a 

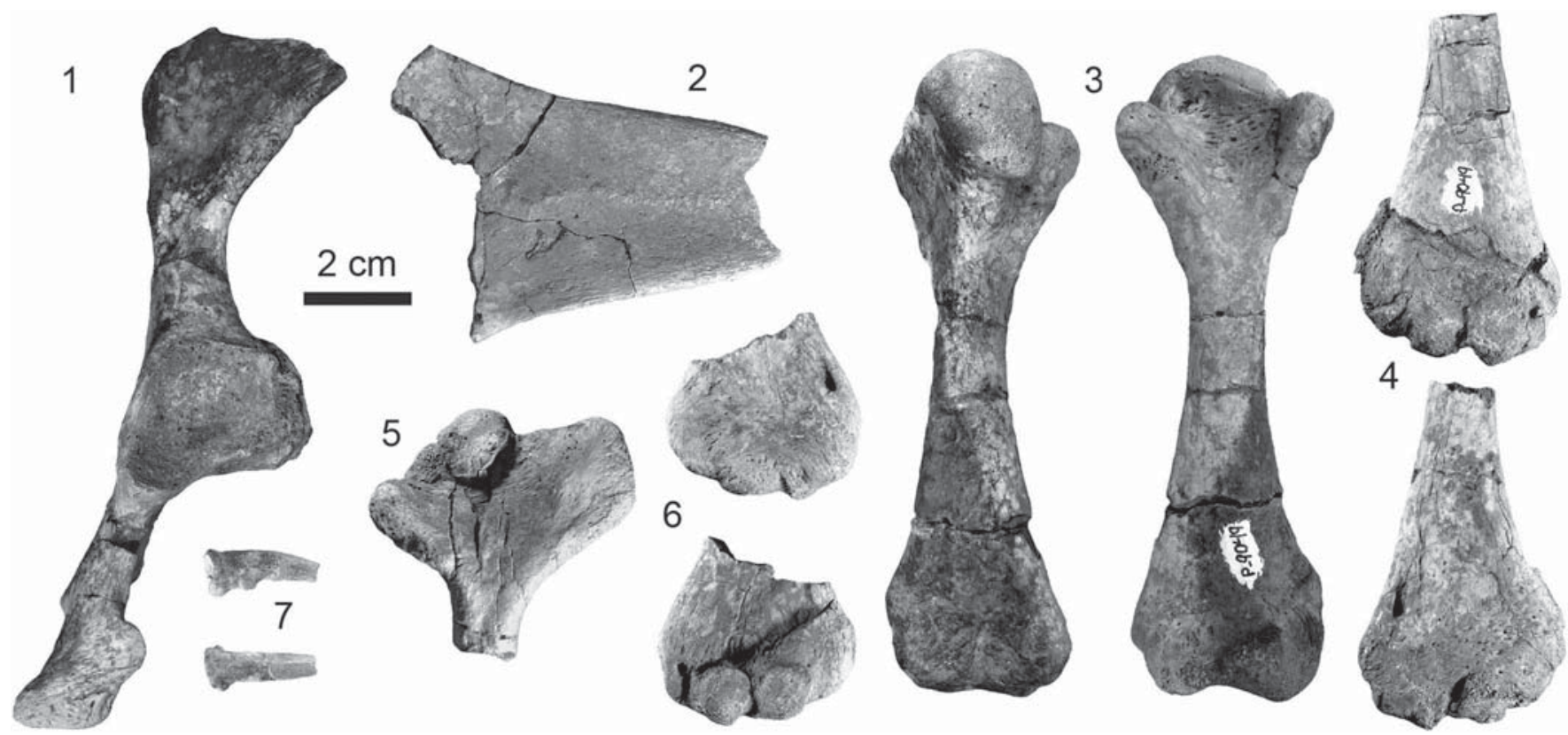

Figure 5. Photographs of the appendicular elements of the holotype of Neurankylus torrejonensis (NMMNH P-9049), Paleocene (Torrejonian) of New Mexico. (1) Lateral view of the left acetabulum and pubis; (2) dorsal view of the epipubis; (3) right femur in dorsal (left) and ventral (right) views; (4) distal end of left humerus in ventral (top) and dorsal (bottom) views; (5) proximal end of right humerus in dorsal view; (6) distal end of right humerus in dorsal (top) and ventral (bottom) views; (7) distal phalanx in lateral (top) and ventral (bottom) views.

basal baenid. The cranial anatomy of this particular specimen has been used in the phylogenetic analyses of Brinkman and Nicholls (1993) and Lyson and Joyce (2009a, b; 2010; 2011) but was never described or figured, and the associated skeleton has largely been ignored. In addition, these analyses universally followed Gaffney (1972) by regarding all available Neurankylus material ranging from the Campanian to Paleocene as belonging to a single species, $N$. eximius. We follow Sullivan et al. (2013) and Larson et al. (2013) and recognize three Late Cretaceous Neurankylus taxa and the new Paleogene taxon described herein, $N$. torrejonensis.

The shell of $N$. torrejonensis is largely identical to that of the three described species of Late Cretaceous Neurankylus. Large size, a complete ring of marginal scales, wide vertebral scales, a small and undivided cervical scale, and four pleural scales are found in all species of Neurankylus. Differences are mostly found in the development of a midline ridge and the presence of scalloping along the posterior margin of the shell. The oldest described Neurankylus is Neurankylus lithographicus from the Santonian, whereas N. torrejonensis is the youngest from the Torrejonian, indicating that shell anatomy went largely unchanged for nearly 25 million years. No other baenid lineage shows such morphological stasis in the shell for such a long period.

While the shells are remarkably similar among the four species of Neurankylus, various differences exist in cranial morphology. The only available skull of $N$. lithographicus consists of a single fragment of an otic chamber (Larson et al., 2013), while the only known skull of $N$. eximius consists of a skull roof, otic chambers, and basicranium (Brinkman and Nicholls, 1993). No skull material is currently available for $N$. baueri. Both $N$. eximius and $N$. torrejonensis have a thickened skull roof; however, only $N$. torrejonensis has the impressions of scales preserved. The frontal broadly enters the orbital margin in $N$. eximius but only narrowly enters the orbital margin in $N$. torrejonensis as a result of an enlarged prefrontal exposure on the dorsal skull roof in the latter taxon. The upper temporal emargination is much better developed in $N$. torrejonensis than in $N$. eximius. The secondary reduction of the upper temporal emargination is broadly found in Paleocene baenids (e.g., Palatobaena spp., Baena arenosa, 'Baena' affinis, Chisternon undatum, etc.), possibly the result of increased predation from small mammals following the $\mathrm{K} / \mathrm{T}$ extinction event (Lyson and Joyce, 2009b).

A thick skull roof, weak temporal emarginations, presence of lingual ridges on both the maxilla and lower jaw, and a deep and narrow lower jaw with a distinct medial hook allow Neurankylus torrejonensis to be identified easily. However, a lack of hierarchically nested characters prevents us from resolving phylogenetic affinities within the Neurankylus clade (Fig. 6). Indeed, the four recognized species are remarkably similar to one another, but differences and shared characters do exist. Both southern taxa, $N$. torrejonensis and $N$. baueri, have a narrow fifth vertebral and a scalloped posterior margin of the shell, while the northern taxa, N. lithographicus and N. eximius, have a fifth vertebral scale that is just as wide as the previous four vertebrals and an unscalloped posterior shell margin. The prefrontal is much larger in $N$. torrejonensis than in $N$. baueri and prevents the frontal from broadly entering the orbital margin in $N$. torrejonensis. Unlike the other species of Neurankylus, $N$. torrejonensis completely fuses up its shell as an adult.

Our revised phylogenetic analysis (Fig. 6) closely resembles previous analyses (e.g., Brinkman and Nicholls, 1993; Lyson and Joyce 2009a, b; 2010; 2011) by placing Neurankylus spp. outside of Baenodda but in a position more derived than 

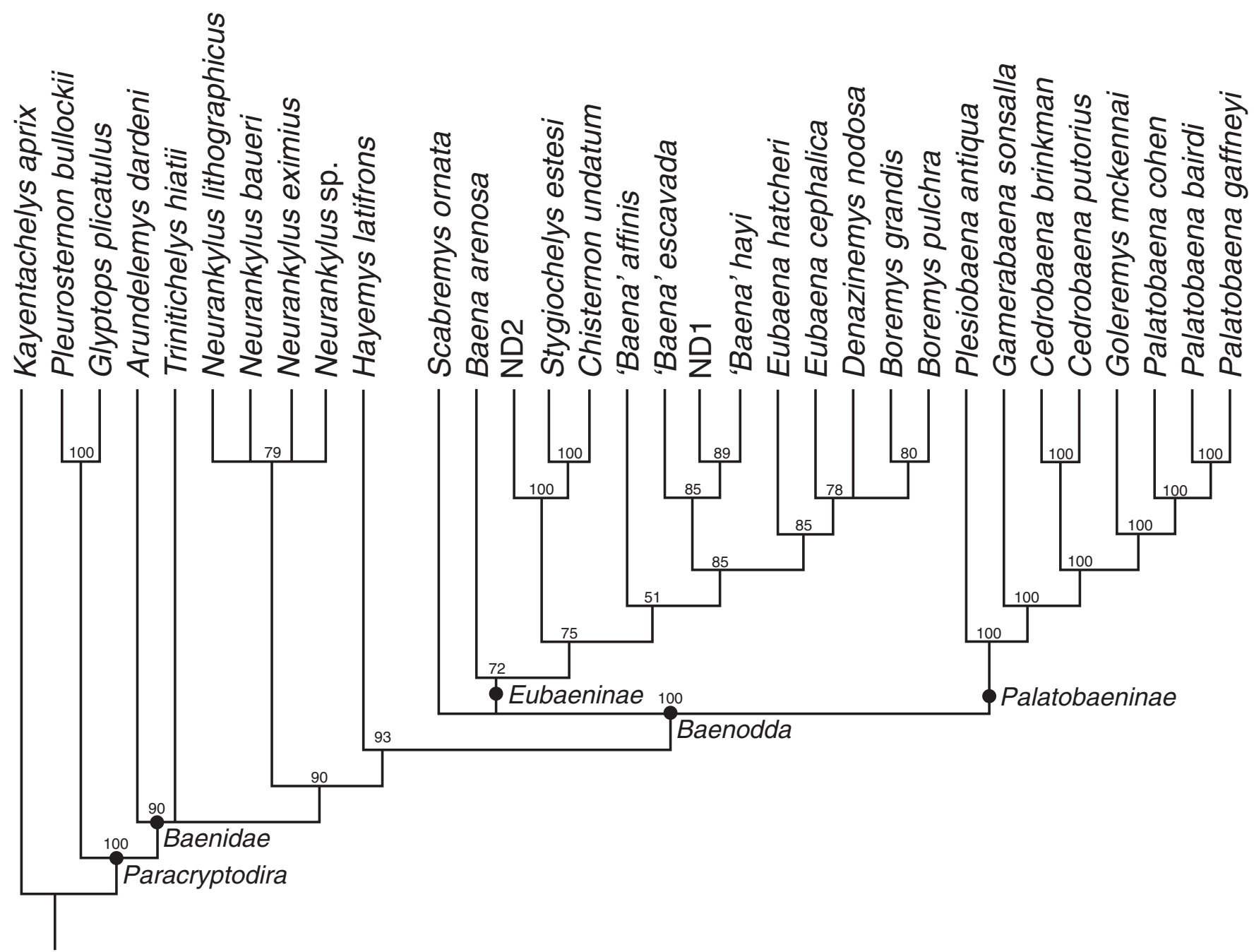

Figure 6. Fifty percent majority rule tree topology resulting from the phylogenetic analysis presented herein. Numbers above nodes are bootstrap support values (Felsenstein, 1985) with 1,000 replicates.

Arundelemys dardeni Lipka et al., 2006 and Trinitichelys hiatti. Our analysis also resembles previous studies by retrieving two primary clades of Baenodda, Eubaeninae and Palatobaeninae (sensu Joyce and Lyson, 2015), but minor differences are apparent. In particular, Cedrobaena brinkman and Ce. putorius are found as sister groups and therefore placed in a single genus to reduce use of monotypic genera. Goleremys mckennai Hutchison, 2004 is placed deep within Palatobaeninae as sister to Palatobaena. The genera topology within Eubaeninae is similar to previous analysis, but the split of Baena arenosa (sensu Gaffney, 1972) into two taxa (i.e., Baena arenosa and 'Baena' affinis sensu Joyce and Lyson, 2015) has a significant effect in that 'Baena' affinis is placed as sister to the clade formed by Boremys spp. and Eubaena spp., while Baena arenosa is recognized as the most basal representative of Eubaeninae. Most notably, the Eocene eubaenines do not form a monophyletic clade anymore. We are somewhat wary of this novel topology as it implies that most Eocene baenid lineages have undetected ancestral lineages that reach at least back to the Campanian. However, given that we were limited to using historical sources of morphological information for these taxa — most morphological data summarized by Gaffney (1972) pertain to chimeras - we are certain that the scoring of these taxa is suboptimal. We therefore encourage the thorough redescription of all available Eocene baenid material.

Unlike the majority of baenid skeletons that are normally found in riverine sandstone deposits, the Neurankylus skeleton described herein was collected from a red shale layer interpreted as an overbank deposit. The lithology around associated skeletons can be used to interpret the paleoecology for extinct animals (e.g., Joyce and Lyson, 2011; Lyson and Longrich, 2011; etc.) While only a single data point, this is the only known skeleton of Neurankylus spp. and weakly suggests that Neurankylus spp. may have preferred ponded water environments over riverine environments. This hypothesis is supported by the fact that despite over 100 years of intense collecting efforts in the latest Cretaceous and the discovery of hundreds of baenid skeletons in sandstone, not a single Neurankylus spp. skeleton has been discovered in a sandstone deposit. As with most paleontological hypotheses, the validity of our hypothesis will be tested with the discovery of additional Neurankylus skeletons. Finally, Neurankylus spp. lacks the distinctly broadened triturating surfaces indicative of a durophagous diet found in the majority of baenid turtles, indicating Neurankylus spp. was not durophagous. 
Rather, the parallel-sided and complete labial and lingual ridges (Fig. 3) indicate a generalized diet.

\section{Acknowledgments}

We thank M. Fox and V. Yarborough (Yale Peabody Museum [YPM]) for preparing and piecing the holotype of Neurankylus torrejonensis back together and B. Roach (YPM) for making the beautiful illustrations that we utilized in Figure 3.

\section{References}

Archibald, J.D., 1977, Fossil Mammalia and Testudines of the Hell Creek Formation, and the geology of the Tullock and Hell Creek formations, Garfield County [Ph.D. dissertation]: University of California, Berkeley, $694 \mathrm{p}$.

Archibald, J.D., and Hutchison, J.H., 1979, Revision of the genus Palatobaena (Testudines, Baenidae), with the description of a new species: Postilla, v. 177 , p. $1-19$.

Brinkman, D.B., 2003, Anatomy and systematics of Plesiobaena antiqua (Testudines: Baenidae) from the mid-Campanian Judith River Group of Alberta, Canada: Journal of Vertebrate Paleontology, v. 23, p. 146-155.

Brinkman, D.B., and Nicholls, E.L., 1991, Anatomy and relationships of the turtle Boremys pulchra (Testudines: Baenidae): Journal of Vertebrate Paleontology, v. 11, p. 302-315.

Brinkman, D.B., and Nicholls, E.L., 1993, The skull of Neurankylus eximius (Testudines: Baenidae) and a reinterpretation of the relationships of this taxon: Journal of Vertebrate Paleontology, v. 13, p. 273-281.

Cope, E.D., 1873, On the extinct Vertebrata of the Eocene of Wyoming, observed by the expedition of 1872, with notes on the geology: United States Geological Survey of the Territories, v. 6, p. 545-649.

Cope, E.D., 1877, On reptilian remains from the Dakota beds of Colorado: Proceedings of the American Philosophical Society, v. 17, p. 193-196.

Evans, J., and Kemp, T.S., 1975, The cranial morphology of a new Lower Cretaceous turtle from southern England: Palaeontology, v. 18, p. $25-40$.

Felsenstein, J., 1985, Confidence limits on phylogenies: An approach using the bootstrap: Evolution, v. 39, p. 783-791.

Gaffney, E.S., 1972, The systematics of the North American family Baenidae (Reptilia, Cryptodira): Bulletin of the American Museum of Natural History, v. 147, p. 241-320.

Gaffney, E.S., 1975, A phylogeny and classification of the higher categories of turtles: Bulletin of the American Museum of Natural History, v. 155, p. $387-436$.

Gaffney, E.S., 1983, The cranial morphology of the extinct horned turtles, Meiolania platyceps, from the Pleistocene of Lord Howe Island, Australia: Bulletin of the American Museum of Natural History, v. 175, p. 364-479.

Gaffney, E.S., and Hiatt, R., 1971, A new baenid turtle from the Upper Cretaceous of Montana: American Museum of Natural History Novitates, v. 2443 , p. $1-9$.

Gilmore, C.W., 1916, Contributions to the geology and paleontology of San Juan County, New Mexico. 2. Vertebrate faunas of the Ojo Alamo, Kirkland, and Fruitland formations: United States Geological Survey Professional Paper 98, p. 279-308.

Gilmore, C.W., 1920, New fossil turtles, with notes on two described species: Proceedings of the United States National Museum, v. 56, p. 113-132.

Goloboff, P.A., Farris, J., and Nixon, K., 2008, A free program for phylogenetic analysis: Cladistics, v. 24, p. 774-786.

Hay, O.P., 1908, The Fossil Turtles of North America: Washington, DC, Carnegie Institution of Washington, publication no. 75, $568 \mathrm{p}$.

Holroyd, P., and Hutchison, J.H., 2002, Patterns of geographic variation in latest Cretaceous vertebrates: Evidence from the turtle component, in Hartman, J.H., Johnson, K.R., and Nichols, D.J., eds., The Hell Creek Formation and Cretaceous-Tertiary Boundary in the Great Plains: An Integrated Continental Record of the End of the Cretaceous: The Geological Society of America Special Paper 361, p. 177-190.

Hutchison, J.H., 1984, Determinate growth in the Baenidae (Testudines): Taxonomic, ecologic and stratigraphic significance: Journal of Vertebrate Paleontology, v. 3, p. 148-151.

Hutchison, J.H., and Archibald, J.D., 1986, Diversity of turtles across the Cretaceous/Tertiary boundary in northeastern Montana: Palaeogeography, Palaeoclimatology, Palaeoecology, v. 55, p. 1-22.

Hutchison, J.H., 2004, A new eubaenine, Goleremys mckennai, gen. et sp. n., (Baenidae: Testudines) from the Paleocene of California: Bulletin of the Carnegie Museum of Natural History, v. 36, p. 91-96.
Hutchison, J.H., and Holroyd, P.A., 2003, Late Cretaceous and early Paleocene turtles of the Denver Basin, Colorado: Rocky Mountain Geology, v. 38, p. 121-142.

Hutchison, J.H., Knell, M.J., and Brinkman, D.B., 2013, Turtles from the Kaiparowits Formation, Utah, in Titus, A.L., and Loewen, M.A., eds., At the Top of the Grand Staircase, The Late Cretaceous of Southern Utah: Bloomington, Indiana University Press, p. 295-318.

Joyce, W.G., and Lyson, T.R., 2011, New material of Gilmoremys lancensis nov. comb. (Testudines: Trionychidae) from the Hell Creek Formation and the diagnosis of plastomenid turtles: Journal of Paleontology, v. 85, p. 442-459.

Joyce, W.G., and Lyson, T.R., 2015, A review of the fossil record of turtles of the clade Baenidae: Bulletin of the Peabody Museum of Natural History, v. 56, p. $147-183$.

Klein, I.T., 1760, Klassification und kurze Geschichte der vierfüßigen Thiere [translation by F. D. Behn]: Lübeck, Germany, Jonas Schmidt, 381 p.

Lambe, L.M., 1902, New genera and species from the Belly River Series (mid-Cretaceous): Contributions to Canadian Palaeontology, v. 3, p. 23-81.

Larson, D.W., Longrich, N.R., Evans, D.C., and Ryan, M.J., 2013, A new species of Neurankylus from the Milk River Formation (Cretaceous: Santonian) of Alberta, Canada, and a revision of the type species N. eximius, in Brinkman, D.B., Holroyd, P.A., and Gardner, J.D., eds., Morphology and Evolution of Turtles: Dordrecht, Springer, p. 389-405.

Leidy, J., 1870, Description of Emys jeanesi n. sp., Emys haydeni n. sp., Baena arenosa n. g. n. sp., and Saniwa ensidens n. g. n. sp.: Proceedings of the Academy of Natural Sciences of Philadelphia, v. 1870, p. 123-124.

Leidy, J., 1871a, Remarks on fossil vertebrates from Wyoming: American Journal of Science, v. 2, p. 372-373.

Leidy, J., 1871b, Report on the vertebrate fossils of the Tertiary formations of the West: Preliminary report of the United States Geological Survey of Wyoming and Portions of Contiguous Territories, v. 4, p. 340-370.

Lipka, T.R., Therrien, F., Weishampel, D.B., Jamniczky, H.A., Joyce, W.G., Colbert, M.W., and Brinkman, D.B., 2006, A new turtle from the Arundel Clays (Potomac Formation, Early Cretaceous) of Maryland, U.S.A: Journal of Vertebrate Paleontology, v. 26, p. 300-307.

Lyson, T.R., and Joyce, W.G., 2009a, A new species of Palatobaena (Testudines: Baenidae) and a maximum parsimony and Bayesian phylogenetic analysis of Baenidae: Journal of Paleontology, v. 83, p. $457-470$.

Lyson, T.R., and Joyce, W.G., 2009b, A revision of Plesiobaena (Testudines: Baenidae) and an assessment of baenid ecology across the K/T boundary: Journal of Paleontology, v. 83, p. 833-853.

Lyson, T.R., and Joyce, W.G., 2010, A new baenid turtle from the Upper Cretaceous (Maastrichtian) Hell Creek Formation of North Dakota and a preliminary taxonomic review of Cretaceous Baenidae: Journal of Vertebrate Paleontology, v. 30, p. 394-402.

Lyson, T.R., and Joyce, W.G., 2011, Cranial anatomy and phylogenetic placement of the enigmatic turtle Compsemys victa: Journal of Paleontology, v. 85 , p. $789-801$.

Lyson, T.R., and Longrich, N.R., 2011, Spatial niche partitioning in dinosaurs from the latest Cretaceous (Maastrichtian) of North America: Proceedings of the Royal Society B: Biological Sciences, v. 278, p. 1158-1164.

Lyson, T.R., Joyce, W.G., Knauss, G.E., and Pearson, D.A., 2011, Boremys (Testudines, Baenidae) from the latest Cretaceous and early Paleocene of North Dakota: An 11-million-year range extension and an additional K/T survivor: Journal of Vertebrate Paleontology, v. 31, p. 729-737.

Milner, A.R., 2004, The turtles of the Purbeck Limestone Group of Dorset, southern England: Palaeontology, v. 47, p. 1441-1467.

Russell, L.S., 1934, Fossil turtles from Saskatchewan and Alberta: Transactions of the Royal Society of Canada, v. 28, p. 101-110.

Sinclair, W.J., and Granger, W., 1914, Paleocene deposits of the San Juan Basin, New Mexico: American Museum Bulletin, v. 33, p. 297-316.

Sterli, J., and Joyce, W.G., 2007, The cranial anatomy of the Early Jurassic turtle Kayentachelys aprix: Act Paleontological Polonica, v. 52, p. 675-694.

Sullivan, R.M., Lucas, S.G., Hunt, A.P., and Fritts, T.H., 1988, Color pattern on the selmacryptodiran turtle Neurankylus from the early Paleocene (Puercan) of the San Juan Basin, New Mexico: Contributions in Science, v. 401, p. 1-9.

Sullivan, R.M., Jasinski, S.E., and Lucas, S.G., 2013, Re-Assessment of late Campanian (Kirtlandian) turtles from the Upper Cretaceous Fruitland and Kirtland formations, San Juan Basin, New Mexico, USA, in Brinkman, D. B., Holroyd, P.A., and Gardner, J.D., eds., Morphology and Evolution of Turtles: Dordrecht, Springer, p. 389-405.

Wood, H.E., Chaney, R.W., Clark, J., Colbert, E.H., Jepsen, G.L., Reeside, J.B., and Stock, C., 1941, Nomenclature and correlation of the North American continental Tertiary: Geological Society American Bulletin, v. 52 , p. $1-48$.

Accepted 8 October 2015 


\section{Appendix 1. Sources of morphological information}

'Baena' affinis (sensu Joyce and Lyson, 2015; all Eocene specimens with three inframarginals listed by Hay, 1908, including holotypes of Baena riparia and Baena inflata); 'Baena' escavada (Hay, 1908); Arundelemys dardeni (Lipka et al., 2006); Baena arenosa (sensu Joyce and Lyson, 2015; holotype of Baena sima); Boremys grandis (Sullivan et al., 2013); Boremys pulchra (Brinkman and Nicholls, 1991); Cedrobaena brinkman (Lyson and Joyce, 2009b); Cedrobaena putorius (Gaffney, 1972; Lyson and Joyce, 2009b); Chisternon undatum (Hay, 1908, particularly the holotype of Chisternon hebraicum); Denazinemys nodosa (Sullivan et al., 2013); Eubaena cephalica (Gaffney, 1972); Eubaena hatcheri (Hay, 1908); Gamerabaena sonsalla (Lyson and Joyce, 2010); Glyptops plicatulus (Hay, 1908); Goleremys mckennai (Hutchison, 2004); Hayemys latifrons (Hay, 1908); Kayentachelys aprix (Sterli and Joyce, 2007; personal observation of postcranial material); Neurankylus baueri (Sullivan et al., 2013); Neurankylus eximius (Larson et al., 2013); Neurankylus lithographicus (Larson et al., 2013); Neurankylus torrejonensis n. sp. (personal observation type specimen); Palatobaena bairdi (Gaffney, 1972; Lyson and Joyce, 2009a); Palatobaena cohen (Lyson and Joyce, 2009a); Palatobaena gaffneyi (Archibald and Hutchison, 1979); Plesiobaena antiqua (Brinkman, 2003; personal observation of material); Pleurosternon bullockii (Evans and Kemp, 1975; Milner, 2004; personal observation of skull material); Scabremys ornata (Sullivan et al., 2013); Stygiochelys estesi (Gaffney and Hiatt, 1971); Thescelus rapiens (Hay, 1908, holotype only); Trinitichelys hiatii (Gaffney, 1972, personal observation holotype).

\section{Appendix 2. List of characters used}

1. skull shape in dorsal view: $0=$ skull much wider than long; $1=$ skull as wide as long; $2=$ skull much longer than wide.

2. cranial sculpturing: $0=$ absent; $1=$ present, as in Pleurosternon bullockii.

3. snout shape: $0=$ rectangular; $1=$ pointed.

4. preorbital length: $0=$ short; $1=$ long.

5. orbit shape: $0=$ circular; $1=$ with posterior notch.

6. size of orbit: $0=$ notably small; $1=$ notably large.

7. maxillary height below orbit: $0=$ notably gracile; $1=$ notably tall.

8. orbit laterally defined by bony ridge formed by maxilla: $0=$ absent; $1=$ present.

9. orientation of orbit: $0=$ laterally; $1=$ dorsally.

10. cheek emargination: $0=$ absent; $1=$ minor; $2=$ deep.

11. size of cavum tympanum: $0=$ notably small; $1=$ notably large relative to orbit.

12. upper temporal emargination: $0=$ emargination absent; $1=$ minor; $2=$ notably deep.

13. size of external nares: $0=$ small, significantly smaller than the orbit; $1=$ large, approximately the same size as the orbit.

14. orientation of external nares: $0=$ anteriorly; $1=$ anterodorsally.

15. lingual ridge: $0=$ developed along full length of palate; $1=$ only developed along anterior half of palate; $2=$ absent.

16. hooked premaxilla: $0=$ absent; $1=$ present.
17. shape of triturating surface: $0=$ lingual and labial margins more or less parallel; 1 = lingual and labial margins diverge posteriorly.

18. angle between maxillae: $0=$ acute; $1=$ obtuse.

19. palatal tongue groove: $0=$ broad; $1=$ narrow.

20. sulcus around external narial opening: $0=$ absent; $1=$ present.

21. nasals: $0=$ large; $1=$ reduced; $2=$ absent.

22. prefrontal exposure on skull roof: $0=$ large; $1=$ reduced; $2=$ absent

23. fontal maxilla contact: $0=$ absent; $1=$ present.

24. jugal contribution to orbit: $0=$ large; $1=$ small; $2=$ absent.

25. jugal thickening: $0=$ absent; $1=$ present.

26. squamosal parietal contact: $0=$ present; $1=$ absent.

27. parietal width versus length: $0=$ maximum combined width of parietals less then their length maximum; $1=$ combined width of parietals greater than their length.

28. posterior margin of parietals: $0=$ parietals taper toward posterior margin; $1=$ posterior margin of parietals greatly thickened.

29. supraoccipital crest covered by rounded parietals only: $0=$ absent; $1=$ present.

30. supraoccipital exposure between parietals on skull roof: $0=$ absent; $1=$ minor; $2=$ large.

31. location of foramen praepalatinum: $0=$ entirely within premaxillae; $1=$ within suture of premaxillae with vomer and/or maxillae.

32. foramen palatinum posterius: $0=$ formed by pterygoid and palatine; 1 = formed entirely by palatine.

33. midline contact of pterygoid: $0=$ large; $1=$ small.

34. pterygoid basioccipital contact: $0=$ absent or poorly developed; 1 = well developed.

35. contribution of opisthotic to foramen stapedio-temporale: $0=$ absent; $1=$ present.

36. hooked mandible: $0=$ absent; $1=$ present.

37. splenial: $0=$ large; $1=$ reduced; $2=$ absent.

38. tubercle on posterolateral edge of dentary: $0=$ absent; $1=$ present.

39. height of dentary: $0=$ high, mandible massive; $1=$ low, mandible gracile.

40. carapace length: $0=$ less than $50 \mathrm{~cm} ; 1=$ greater than $50 \mathrm{~cm}$.

41. shell sculpturing : $0=$ smooth; $1=$ small, raised tubercles, as in Pleurosternon bullockii; $2=$ elongate, raised welts; 2 = elongate crenulations.

42. fusion of shell in adults: $0=$ absent; $1=$ present.

43. anteriorly scalloped shell: $0=$ absent; $1=$ present.

44. scalloping of posterior carapacial margin: $0=$ absent; $1=$ present, but slight; $2=$ present and distinct.

45. costal fontanelles: $0=$ absent; $1=$ present.

46. preneural: $0=$ absent; $1=$ present.

47. contact of neural VI with costal VII: $0=$ absent; $1=$ present.

48. number of suprapygals and pygals: $0=$ three; $1=$ two; $2=$ one.

49. cervical scutes: $0=$ single; $1=$ divided.

50. size of cervical, whenever only one is present: $0=$ wider than long; $1=$ longer than wide.

51. nuchal scute: $0=$ absent; $1=$ present.

52. prepleural scute: $0=$ absent; $1=$ present.

53. postpleural scute: $0=$ absent; $1=$ present.

54. supramarginal scales: $0=$ absent; $1=$ present. 
55. shape of vertebral scute I: $0=$ narrows anteriorly; $1=$ narrows posteriorly.

56. shape of vertebral scute III: $0=$ wider than long; $1=$ about as wide as long; $2=$ longer than wide.

57. contribution of most posterior vertebral to carapacial margin: $0=$ absent; $1=$ present.

58. shape of vertebral scute V: $0=$ width of vertebral $\mathrm{V}$ greater or equal to that of vertebral IV; $1=$ width of vertebral $\mathrm{V}$ small than that of vertebral IV.

59. epiplastral processes: $0=$ present; $1=$ absent.

60. shape of anterior plastral lobe: $0=$ rectangular; $1=$ triangular.

61. plastral lobe dimensions: $0=$ posterior lobe larger than anterior lobe; $1=$ anterior lobe larger than posterior lobe.

62. extragulars: $0=$ large, similar in size to intergulars; $1=$ greatly reduced relative to intergulars; $2=$ absent.

63. medial contact of extragulars: $0=$ absent; $1=$ present.

64. sigmoidal extragular/humeral sulcus: $0=$ absent; $1=$ present.

65. sigmoidal femoral/anal sulcus: $0=$ absent; $1=$ present.

66. axillary buttresses: $0=$ poorly developed, only minor contact with costals; $1=$ well developed, broad contact with costals.

67. inguinal buttresses: $0=$ poorly developed, no contact with costals; $1=$ well developed, broad contact with costals.

68. formed cervical vertebrae: $0=$ absent; $1=$ present.

69. length of distal caudals: $0=$ same length as proximal caudals; 1 = significantly longer than proximal caudals.

\section{Appendix 3. Character/taxon matrix used in this study}

Missing data are coded as '?.' Taxa may be coded with two character states if they display multiple morphologies (polymorphic) or when their morphology is perceived as intermediate. $a=0 / 1 ; b=1 / 2$.

Kayentachelys aprix $100002000001000000000000000000-000000000000000$ 000000010010000000000 ?

Pleurosternon bullockii

$2110020001210120000000020000010 ? ? 01 ? ? ? ? 01000000000$ 00000000?0 100000?0?

Glyptops plicatulus

$21100200012 ? 01210000000200000 ? 00 ? 0 ? 100101000000100$ 000000000010000000 ?

Arundelemys dardeni

$11 \mathrm{a} 002000 ?$ 2?00100000 00020?0?00 00011????? ??????????

????????? ?????????

Hayemys latifrons

10?0??0001 2110?0?000 00??010?0? ?1010????? ??????????

????????? ?????????

Neurankylus baueri

?????????? ?????????? ?????????? ?????????1 0001001001

000000011010000111 ?
Neurankylus eximius

?????????? 2????????? ?0?????11? ??011????1 00010?1001 $00000000100010011 ? ?$

Neurankylus lithographicus

?0???????? ????????? ?0???????0 ??01a????1 010?00???? $00000000100000011 ? ?$

Neurankylus torrejonensis

0000?????? 1??0?0?0?? 0001?0011? ??01?1?001 01010???01

$00000 ? 0110$ ?0a0?11??

Trinitichelys hiatti

$11 \mathrm{a} 0020001210010000001$ ?b0a0000 ?0011????0 100?00??00 00?000??10 0000?110?

Scabremys ornata

?????????? ?????????? ?????????? ?????????0 21120???00 $0000011010011 \mathrm{a} 011 ? ?$

Thescelus insiliens

????????? ????????? ?????????? ????????0 11?100??00 00000b0010 01101????

Baena arenosa

10100110011 1??1101000 ????00?1?? ?0?1?1?010 01010???1$0000 ? 210100011111 ? ?$

'Baena' affinis

10??0???0? ????1?1000 ?11????0?? ???????0?0 3001001210100121010001011111

'Baena' escavada

?????????? ?????????? ?????????? ?????????0 01020????? $0 \mathrm{a} 00 ? 21010001 \mathrm{a} 111 ? ?$

'Baena' hayi

????????? ????????? ????????0? ?????????0 01020???1$01001010110111111 ? ?$

Boremys grandis

????????? ????????? ?????????? ?????????1 201201??1$1111121 ? ? 00111011 ? ?$

Boremys pulchra

101100100? 2?11?010?0 111?010001??01001?10 201201111$1111021011011 \mathrm{a} 01101$

Chisternon undatum

101012a001 12?11010001110001101 ?1110020110001011? 1- 11 ? $012 ? 01001101111$ ?

Denazinemys nodosa

?????????? ????????? ?????????? ?????????0 211200?21$11001210100010011 ? ?$

Eubaena cephalica

$101100200122111010101112010001100100111 ?$ ?????????? ????????? ????????? 
Eubaena hatcheri

????????? ?????????? ?????????? ?????????0 000200121$110010101000 \mathrm{a} 0011 ? ?$

Stygiochelys estesi

$101012100121111010001111010001111110 ? 11 ?$ ?????????

?????????? ?????????

Cedrobaena brinkman

1??0011002 22??1?1000 21110100011001000110 010?00?? $0000000010110210 ? 11 ?$ ?

Cedrobaena putorius

$1 ? ? 001110222 ? ? 1 ? 1000211101001010010 ? 0 ? ? ?$ ????????? ????????? ?????????

Gamerabaena sonsalla

101001111? 2?11101000 11120???0? ?0010????? ??????????

????????? ?????????

Goleremys mckennai

$101001210122 ? 1101000011001000 ? 10010 ? ? ? ? ?$ ?????????

?????????? ?????????
Palatobaena bairdi

00-0012111 $221120110111101101021001 ? 0011 ?$ ????????? ?????????? ?????????

Palatobaena cohen

00-00121112211201101 11111100011001000110 010?10?? $0000001010110210111 ?$ ?

Palatobaena gaffneyi

00-0012111 $2211201101111111010210110 ? ? ? ? ? ? ? ? ? ? ? ? ? ?$ ?????????? ?????????

Plesiobaena antiqua

10100110012111101000111201000110110001100000101100 0000011011011011111

ND 1

101101000122111010101112010001 1001001a10 01120a1210100111011011011111

ND 2

$1010121001211110100011120100011001001110000 \mathrm{~b} 01111$ $11001 \mathrm{~b} 1010001101111$ 